\title{
Trajetória de um Grupo de Professores de Matemática: ensinando e aprendendo em colaboração
}

\author{
The Trajectory of a Mathematics Teacher Group: \\ teaching and learning by collaboration
}

Nielce Meneguelo Lobo da Costal

Maria Elisabette Brisola Brito Prado ${ }^{2}$

Aparecida Rodrigues Silva Duarte ${ }^{3}$

\begin{abstract}
Resumo
Neste artigo analisamos a trajetória de um grupo de professores de Matemática participantes de Projeto do Programa OBEDUC da CAPES buscando compreender as contribuições para seu desenvolvimento profissional. A fundamentação teórica veio de Murphy e Lick, referente aos grupos de estudos; de Zeichner para prática reflexiva, de Ponte, para desenvolvimento profissional e de Boavida \& Ponte, quanto ao trabalho colaborativo. A pesquisa qualitativa utilizou para coleta de dados questionário, depoimentos e gravações dos encontros. A análise foi interpretativa e por tratamento com o software CHIC. As metodologias utilizadas nos processos formativos envolveram conteúdos matemáticos, estratégias pedagógicas e compartilhamento das experiências em vários contextos (no grupo, na escola, nos eventos). Assim contribuíram para que o professor desempenhasse um novo papel, o de formador, e propiciaram a construção de uma cultura de grupo possibilitando a cada participante ensinar e aprender com o outro.
\end{abstract}

Palavras-chave: Prática Docente; CHIC; Trabalho colaborativo; Desenvolvimento profissional

\begin{abstract}
In this paper, we analyze the trajectory of a group of Mathematics teachers, which are participants of a Project from CAPES OBEDUC Program seeking to understand the contributions to their professional development. The theoretical foundation came from Murphy and Lick, referring to the study groups; of Zeichner for reflective practice; Ponte, to professional development and Boavida \& Ponte, to collaborative work. The qualitative research used questionnaires, interviews and meetings recordings to collect data. The analysis was interpretative and by treatment with CHIC software. The methodologies used in educational processes involved mathematical content, teaching strategies and sharing of experiences in various contexts (in the group, at school, in the events). Thus contributed to the teacher to play a new role, the coach, and led to the construction of a group culture, allowing each participant to teach and learn from each other.
\end{abstract}

Keywords: Teaching Practice; CHIC; Collaborative Work Professional Development.

\footnotetext{
${ }^{1}$ Doutora em Educação e Currículo pela Pontifícia Universidade Católica de São Paulo (PUC/SP). Professora do Programa de Pós-graduação em Educação Matemática da Universidade Anhanguera de São Paulo (UNIAN/SP), São Paulo, Brasil. E-mail: nielce.lobo@gmail.com.

${ }^{2}$ Doutora em Educação e Currículo pela Pontifícia Universidade Católica de São Paulo (PUC/SP). Professora do Programa de Pós-graduação em Educação Matemática da Universidade Anhanguera de São Paulo (UNIAN/SP), E-mail: bette.prado@gmail.com.

${ }^{3}$ Doutora em Educação Matemática pela Pontifícia Universidade Católica de São Paulo (PUC/SP). Professora do Programa de Pós-graduação em Educação da Universidade do Vale do Sapucaí (UNIVAS/MG), E-mail: aparecida.duarte6@gmail.com.
} 


\section{Introdução}

O trabalho docente sempre foi tarefa complexa, uma vez que ele lida com o preparo das novas gerações. Este é um trabalho particularmente desafiador, por lidar com o saber e a formação da pessoa preparando-a para atuar como indivíduo, cidadão e profissional na sociedade. Enfim, é o trabalho de alguém cujas ações têm impacto no futuro dos seres com os quais interage, os alunos.

Nessa perspectiva, a própria essência da profissão aponta para a necessidade de o professor ser um profissional ávido por aprender, o que significa dizer que para ensinar é preciso que aprenda sempre, se reinvente e, reconstrua seus conhecimentos.

Assim, as propostas de formação continuada para professores devem criar situações que propiciem ao professor a aprender de forma autônoma ao longo da vida, especialmente ao considerarmos como desenvolvimento profissional do docente o processo de (re)construção de conhecimentos. Para isto torna-se necessário ampliar e diversificar as ações formativas de modo que o professor possa assumir uma postura ativa de aprendente incluindo a própria prática pedagógica como um objeto contínuo de estudo e de reflexão. Para que ocorra reflexão sobre a prática, segundo Schön (1992) e Zeichner (1993), o professor precisa reconstituir sua experiência da docência e discuti-la com seus pares, para que todos os envolvidos possam, em colaboração, aprender e ensinar um ao outro.

Uma das estratégias que vem sendo utilizada nesse sentido é a constituição de grupos de professores que se reúnem sistematicamente para estudar sobre os processos de ensino e de aprendizagem relacionados ao contexto de atuação.

Com esse enfoque, apresentamos no artigo um recorte de uma pesquisa vinculada a projeto maior no âmbito do Programa Observatório da Educação ${ }^{4}$, na área de educação continuada. O referido projeto, intitulado Educação Continuada do Professor de Matemática do Ensino Médio: Núcleo de Investigações sobre a reconstrução da prática pedagógica, aqui denominado por Projeto "OBEDUC Práticas", intenta constituir e analisar um núcleo investigativo com e sobre o trabalho docente do professor de Matemática, com vistas à reconstrução da prática pedagógica. Em consonância com este projeto, esta pesquisa tem como objeto analisar a trajetória formativa de um grupo de estudo de professores de Matemática da Educação Básica, buscando compreender os elementos que podem contribuir para o desenvolvimento profissional dos professores participantes.

\section{Grupos de estudos e trabalho colaborativo}

O termo "grupo de estudos" neste texto é entendido na acepção de Murphy e Lick (1998), para os quais esse tipo de organização humana, normalmente congrega pequeno

\footnotetext{
${ }^{4}$ O Programa tem gestão conjunta da Coordenação de Aperfeiçoamento de Pessoal de Nível Superior CAPES e do Instituto Nacional de Estudos e Pesquisas Educacionais Anísio Teixeira - INEP. Para saber mais: $<$ http://www.capes.gov.br/educacao-basica/observatorio-da-educacao>.
} 
número de indivíduos e costuma promover crescimento e empoderamento dos participantes, visto que impulsiona o compartilhamento de anseios e ideias, o planejamento, a aprendizagem mútua e a construção de novos conhecimentos. Para esses autores, num grupo de estudos cada participante aprende com o outro, ao longo das discussões e debates e aprende por meio do trabalho conjunto e das produções coletivas.

Nos grupos de estudo se estabelecem objetivos e metas comuns os quais orientam os estudos e auxiliam a mobilizar os integrantes, envolvendo-os no trabalho coletivo de modo a atingir os propósitos estabelecidos. Assim sendo, nos grupos de estudos pode-se criar um ambiente de colaboração e cumplicidade que é favorável ao crescimento dos indivíduos, tanto no aspecto pessoal quanto profissional.

A participação nos grupos de estudo permite quebrar o isolamento característico da profissão docente, isolamento este que tem sido estudado por diversos autores, tais como Hargreaves (1998), que enfatiza tanto o individualismo quanto o isolamento como sendo características que fazem parte da cultura dos professores. No trabalho docente diário, tarefas como o preparo de aulas, materiais e atividades para os alunos são comumente feitas de modo individual. Lortie (1975 apud Hargreaves, 1998) foi um dos primeiros a discutir a prevalência do individualismo na profissão docente de forma sistemática; ele comparou metaforicamente a estrutura e disposição das salas de aula nas escolas com a estrutura de uma caixa de ovos. Essa estrutura põe em evidência a segregação entre os espaços de aula, a atuação autônoma e individualizada dos professores, sempre apartados uns dos outros e o confinamento ao cenário "professor-seus alunos", de modo que os docentes pouco observam e compreendem o trabalho dos colegas, assim como têm raras oportunidades, no dia-a-dia da profissão, de desenvolver trabalho compartilhado com colegas professores e demais alunos da escola.

Vale ressaltar que o isolamento docente ao mesmo tempo que dá privacidade ao professor, faz com que ele receba pouco feedback de outros indivíduos quanto ao seu mérito, valor e competência. Entretanto, o individualismo é um fenômeno social e cultural complexo, com diversos significados, nem todos negativos. $\mathrm{O}$ isolamento docente pode favorecer a inventividade, a criatividade e o estilo individualizado de ensinar, que pode trazer benefícios para o processo de aprendizagem dos alunos, contudo pode falhar nos momentos de enfrentamento de novos desafios e de incertezas do professor quanto ao trabalho docente que realiza por detrás das portas fechadas da sala de aula.

As preocupações e descobertas sobre a cultura docente apontadas por Hargreaves em 1998 são ainda pertinentes, mesmo passados quase 20 anos. As culturas de colaboração e o aperfeiçoamento contínuo têm sido considerados como fundamentais para a redução da incerteza dos professores e como estratégia para fomentar o desenvolvimento profissional. Os professores podem aprender uns com os outros, com apoio do grupo podem se permitir ousar e correr riscos na docência compartilhando acertos e discutindo correções para situações conflituosas. Assim, vão desenvolvendo em conjunto suas competências. Segundo afirmou Shulman (1989), em conferência realizada na Trinity University, San Antonio, USA, a colegialidade e a colaboração melhoram o moral e a satisfação dos docentes e são necessárias 
para que eles se beneficiem de suas experiências e continuem a crescer ao longo da carreira.

Os grupos de estudos constituídos por professores podem se aproximar do que Hargreaves (1998) denominou de colegialidade real, com as seguintes características: fomentar o debate regular sobre a natureza e fundamentar a ação docente que realizam ou planejam; abordar situações para aprofundamento do saber profissional, auxiliar o enfrentamento dos problemas baseado tanto nos estudos coletivos quanto nos contributos de cada um, assumir decisões coletivas adotadas por deliberação fundamentada, contribuir para a ação e decisão individual a partir do debate com os pares.

Quanto à prática docente, Murphy e Lick (1998) enfatizam que, ela se transforma quando o professor se apoia em um grupo de estudos constituído por seus pares, pois esses podem se constituir em ambiente propício para as trocas, explicações e para avaliar práticas adequadas às necessidades particulares de seus alunos. $\mathrm{O}$ contato com os colegas, a ajuda mútua, o trabalho em colaboração e as reflexões conjuntas podem auxiliar o professor a ser mais flexível e inventivo em sua prática. Como ressaltam Mädche e Mallmann (2006, p. 13), estudos e reflexões coletivas no seio do grupo podem contribuir para se construir paulatinamente uma "consciência teórica sobre o fazer pedagógico, na medida em que desvenda e revela, nas discussões que empreende, sua forma de entender, trabalhar e conceber a prática no cotidiano da escola”.

Pesquisadores em Educação Matemática, tais como (Gimenes e Penteado, 2008; Lima, 2009; Silva, 2010), têm referendado, a partir de suas investigações, que a participação em grupos de estudos leva o indivíduo à conscientização do seu potencial para a aprendizagem coletiva, bem como de que podem aprender com seus parceiros e, especialmente, a partir das situações que vivenciam e das reflexões que empreendem ao longo dos estudos. Outras pesquisas também apresentaram entre seus resultados que a aprendizagem ocorrida ao longo dos estudos foi relevante para levar os professores integrantes do grupo a ressignificarem os conceitos matemáticos em pauta, inclusive, os autores Gimenes (2006), Etcheverria (2008) e de Boesing (2009) concluíram que as trocas de experiências docentes ocorridas no grupo impactaram também a atuação em sala de aula. Em particular, Gimenes (2006) apontou que a constituição do grupo por ele investigado foi relevante em promover mudanças na escola e contribuiu para a organização e estruturação de outros grupos de estudos.

Pesquisas com grupos de professores que se reúnem para estudos caracterizando-se por um viés de trabalho colaborativo têm sido foco de trabalhos como os de Lopes (2003), Ferreira (2003) e de Lobo da Costa (2004), os quais apontam que grupos de estudos são propulsores de ambiente propício ao desenvolvimento profissional docente. Segundo Lobo da Costa (2004), em sua pesquisa, os participantes de um grupo assumiram papéis diferenciados, ora atuavam como aprendizes, ora como formadores, ora como docentes e ora como pesquisadores. Nesse tipo de constituição de grupo, salienta a autora, é possível subverter as relações de poder entre formador-formando, pois a flexibilidade para desempenhar diferentes papéis permite que os participantes atuem de maneira conjunta, numa relação de aprendizado 
e desenvolvimento mútuo.

A importância da formação de grupos para estabelecer uma rede de aprendizagem entre docentes também foi um resultado apontado por estudo de Lobo da Costa e Prado (2012). Tal pesquisa evidenciou conexão entre o trabalho colaborativo do grupo e a aprendizagem coletiva. A criação da rede de aprendizagem ocorreu em um processo de compartilhamento de vivências, saberes, reflexões, questionamentos, e experiências profissionais, além de estudos conjuntos sobre o conteúdo curricular que ministram.

Outras pesquisas com grupos de estudos, tais como a de Prado e Lobo da Costa (2012) confirmam que "a constituição de um grupo tem peculiaridades que dependem tanto dos componentes do grupo quanto da motivação para participar do processo de estudos e de aprendizagem com o outro" (p.15). A convivência e o empreendimento dos estudos no grupo evidenciam marcas na trajetória. A primeira marca foi referente à discussão de questões mais periféricas da prática pedagógica, questões tais como - gestão da sala de aula, disciplina e motivação dos alunos, entre outras, seguida pela discussão de aspectos pessoais da docência, tais como a forma de ensinar, as estratégias próprias, metodologias. Na sequência, a terceira marca caracterizou-se pela discussão sobre a compreensão, os significados e a construção dos conceitos matemáticos e, a quarta marca traz a visão focada na reconstrução da prática e na consolidação do grupo, que foi a última a ser evidenciada no caminho trilhado pelas participantes do grupo.

Mais recentemente Vieira (2013) investigou a constituição e desenvolvimento de um grupo de estudos, analisando as características que podem impulsionar a ampliação do conhecimento profissional docente dos integrantes. Os resultados apontaram a importância da existência de um líder do grupo como mediador pedagógico para promover reflexões de modo a auxiliar na construção de conhecimentos e na aprendizagem com o outro.

Os resultados de pesquisas com grupos de professores nos alertaram para a pertinência em investigar o desenvolvimento de tais agrupamentos, em particular aqueles que contemplam trabalhos colaborativos, investigações na sala de aula e estudos teóricos, especialmente pelo potencial destes em promover desenvolvimento profissional dos envolvidos. Além disso, há carência de pesquisa em relação a grupos de estudos conjuntos, constituídos por professores atuantes na Educação Básica e por professores da Universidade, nos quais esses últimos podem assumir o papel de líderes de grupo.

\section{Desenvolvimento profissional e Trabalho Colaborativo}

O desenvolvimento profissional é aqui entendido como um processo interno do professor, influenciado por diversos aspectos da carreira docente, qual seja, a formação inicial, a continuada, as características intrínsecas dos saberes com os quais está envolvido na docência, as experiências e oportunidades profissionais, as crenças, concepções e valores, a vivência nos espaços escolares, o contato com outros docentes, com os alunos, os pais e a comunidade escolar. 
Nesse sentido, seguimos Ponte (1997) que identifica o desenvolvimento profissional como composto pelos movimentos empreendidos pelo professor, que levam à reestruturação de sua prática pedagógica, partindo de reflexão, ação e nova reflexão. É “um processo de crescimento na competência em termos de práticas lectivas e não lectivas, no autocontrolo da sua atividade como educador e como elemento da organização escolar" (p. 44). Assim, o desenvolvimento profissional promove mais do que simplesmente o repensar ou mudar a prática na sala de aula, pois engloba as ações educativas do professor de forma global, abarcando aspectos pessoais e relacionais.

Desenvolvimento profissional é um particular tipo de desenvolvimento que envolve tanto a cognição quanto aspectos emocionais. Focando nos aspectos cognitivos, segundo Vygotsky (1984) o desenvolvimento cognitivo do indivíduo é determinado pela aprendizagem. "O aprendizado é um aspecto necessário e universal do processo de desenvolvimento das funções psicológicas culturalmente organizadas e especificamente humanas" (Vygotsky, 1984, p. 101). Os dois processos, aprendizado e desenvolvimento, são interligados e ocorrem graças às interações do indivíduo com o meio, com os instrumentos, com outros indivíduos. Além disso, "o aprendizado não é unilateral, mas recíproco. Isto é, ao aprender, o indivíduo também "ensina" e interfere no grupo. Os dois processos, aprendizado e desenvolvimento, de origem genética e natureza distinta, acontecem simultaneamente e são interdependentes" (Lobo da Costa, 2004, p. 70).

As possibilidades de aprendizagem viabilizadas por meio do trabalho realizado em conjunto com outros indivíduos são inúmeras, especialmente considerando que processos intrapsicológicos ocorrem a partir da mediação e de processos interpsicológicos. Em adição, vale destacar que aspectos emocionais, tais como, aceitação do grupo, autoestima, etc. entram em ação e podem auxiliar na aprendizagem durante o desenvolvimento de trabalho em colaboração.

Boavida e Ponte (2002) consideram nos processos de educação continuada o trabalho colaborativo como sendo o que ocorre em "casos nos quais diversos intervenientes trabalham conjuntamente, não numa relação hierárquica, mas numa base de igualdade de modo a haver ajuda mútua e a se atingirem objetivos que a todos beneficiem" (p. 45). No trabalho colaborativo diferentes olhares permitem a composição de quadros interpretativos consistentes sobre a questão estudada e investigada.

Diante de tais considerações, as quais têm norteado nossas ações formativas apresentamos a seguir a pesquisa que envolve um grupo de estudos formado por professores da Educação Básica e professores universitários, participantes do Projeto OBEDUC Práticas.

\section{A pesquisa}

O objetivo da pesquisa foi investigar a trajetória de um grupo de estudos quanto às possibilidades de desenvolvimento profissional docente, viabilizadas pelo trabalho colaborativo nele empreendido. Este grupo foi formado por cinco dos professores de 
Matemática atuantes na Educação Básica e duas professoras universitárias. Os professores do grupo são aqui identificados como: [Prof- A], [Prof-B], [Prof-C], [Prof-D] e [Prof-E] de modo a preservar a identidade dos mesmos. Todos ministravam aulas de matemática do $6^{\circ}$ ao $9^{\circ}$ ano do Ensino Fundamental e no Ensino Médio em diferentes escolas, na cidade de São Paulo e na cidade de Guarulhos. São licenciados em Matemática, três deles são titulares de cargo efetivo e dois são professores substitutos. As professoras da Universidade, integrantes do grupo, são: uma doutoranda e sua orientadora.

De modo a viabilizar a constituição de um núcleo de investigações e promover formação continuada para professores de matemática do Ensino Fundamental e do Ensino Médio, no Projeto OBEDUC Práticas, foi estabelecida uma parceria com três Diretorias de Ensino (DE) da Secretaria de Educação do Estado de São Paulo; a DE Norte 2, DE Guarulhos Norte e DE Guarulhos Sul, para a promoção de cursos de formação continuada sobre o ensino de Matemática.

Os professores do grupo, como bolsistas do Projeto, tinham o compromisso de desenvolver dois tipos de ações concomitantemente e articuladas. Uma delas envolvia a participação dos cursos desenvolvidos no Projeto aplicando as atividades propostas, previamente adaptadas por eles, em suas respectivas salas de aula e posteriormente fornecer os registros para discutir com os colegas de curso, com a supervisão e intervenção dos formadores. A outra ação foi a constituição de um grupo de estudos com a participação dos cinco professores da Educação Básica e as duas professoras universitárias. Esse grupo se reunia quinzenalmente em momentos distintos dos cursos, para estudos teóricos, produção de materiais e textos, bem como participar em eventos científicos da área da Educação Matemática, tais como: seminários, colóquios, congressos e outros.

A constituição do grupo de estudos permitiu o estabelecimento de um movimento de integração entre a universidade e as escolas participantes, com o fluxo de informações ocorrendo em ambos os lados.

Assim, nesse contexto, a pesquisa foi desenvolvida com metodologia qualitativa, segundo Amado (2013). Para o autor, na pesquisa qualitativa se considera que o homem é criador de significados e a linguagem traduz mais do que esses significados. Assim sendo, os pesquisadores qualitativos "procuram ver através dos olhos dos outros e segundo a sua perspectiva" (p. 106.) na busca por captar os sentidos e nos processos de análise a ênfase está no tempo, no processo e no contexto. A coleta de dados feita por meio de questionário e de depoimentos orais e escritos, gravações em áudio e vídeo dos encontros de formação continuada e do grupo de estudos.

A análise interpretativa de conteúdo dos dados, originados dos depoimentos dos professores participantes utilizou para definir as unidades de significado as categorias ligadas às características do trabalho colaborativo, identificadas a partir da pesquisa de Lobo da Costa (2004). Assim, as categorias identificadas constituíram um novo cenário de análise, o qual foi desenvolvido com apoio de um método estatístico multidimensional utilizado em 
estudos qualitativos de regras de associação. Este método, segundo Gras \& Almouloud (2002) viabilizado por meio do software CHIC (Classificação Hierárquica Implicativa e Coesitiva) situa-se no campo teórico da análise estatística implicativa (Gras \& Couturier, 2010). O CHIC produz gráficos que representam as sínteses das regras de ocorrência de relações entre seus dados segundo a lógica binária, conforme seja identificada a ocorrência ou não ocorrência de determinado evento, representado pelos valores zero ou um. Esses valores são lançados em uma planilha eletrônica, que é importada pelo CHIC para processar os dados. Os objetivos do uso do software CHIC são:

- Extrair de um conjunto de dados regras de associação com base em regularidades entre os dados (variáveis), cruzando sujeitos (ou objetos) e variáveis (ou categorias).

- Representar em gráficos (implicativo, hierárquico, coesitivo) uma estruturação das variáveis obtida por meio de regras de associação.

- Fornecer um índice de qualidade da associação.

A análise hierárquica realizada nesta pesquisa permitiu estabelecer inter-relações entre os dados agrupados em classes, de acordo com sua intersecção, representando as sínteses das regras em visão holográfica de tipologias em árvores de similaridade. A interpretação das classes foi elaborada a partir dos níveis evidenciados como mais significativos em oposição ou semelhança a outros níveis e classes (Almouloud, 1992; Prado, 2008).

Assim, essa análise feita com base nos referenciais teóricos poderá elucidar os aspectos envolvidos na trajetória do grupo de estudos a fim de compreendermos suas possibilidades, de modo a propiciar o desenvolvimento profissional dos professores participantes. A seguir, descrevemos as atividades do grupo de estudos, seguida da análise e dos resultados dessa investigação.

\section{A Trajetória do Grupo}

Esse grupo de professores participou das ações formativas no período de dois anos, conforme a descrição sucinta apresentada a seguir de cada um dos semestres. Antes, porém, ressaltamos que os cinco professores ao responderem o questionário de entrada, no tocante às expectativas pela participação (professores nos cursos e no grupo de estudos), revelaram estarem motivados por aprender novas metodologias de ensino de matemática que pudessem transformar a ação pedagógica, além disso, consideraram a participação no Projeto como uma oportunidade para crescimento profissional. Todos declararam se envolver frequentemente com formação continuada, participando de cursos de extensão, especialização ou atualização.

A organização das ações formativas do grupo foi composta por quatro fases distintas em função das características e do foco das atividades em que os participantes estiveram envolvidos. As fases foram denominadas: Início de convívio, Consolidação, Manutenção e Integração, as quais são apresentadas sucintamente nos quadros a seguir. 
DOI: http://dx.doi.org/10.20396/zet.v24i3.8648094

Quadro 1: Fase 1 - Início de Convívio

\begin{tabular}{l} 
Descrição Sucinta das Atividades (10 semestre do 1ªno) \\
\hline • Curso-1 de formação continuada: “Resolução de Problemas no Currículo de \\
Matemática nos Anos Finais do Ensino Fundamental” \\
-Participação nas sessões de formação: realização das atividades propostas e discussão \\
sobre as resoluções. \\
-Auxílio nas filmagens, organização da documentação de cada sessão, distribuição de \\
materiais e registro das discussões em diários de anotações. \\
• Encontros do grupo \\
-Estudos prévios sobre o tema do Curso 1 envolvendo leituras, discussões e análises; \\
-Planejamento das ações para dar suporte ao desenvolvimento do Curso 1; \\
-Elaboração de materiais para as sessões do Curso 1: pautas, apostilas, dados, cartões, \\
kits de jogos, etc. \\
-Discussões sobre os acontecimentos que se destacaram durante o Curso 1 em relação \\
à participação de outros colegas cursistas. \\
-Planejamento de intervenções a serem realizadas em sala de aula e adaptações das \\
atividades do Curso 1. \\
-Discussões sobre os efeitos das atividades desenvolvidas em sala de aula.
\end{tabular}

Fonte: Acervo próprio

Os cinco professores estiveram envolvidos simultaneamente tanto nas atividades como cursistas na formação continuada, quanto nas do grupo de estudos. No primeiro semestre participaram do Curso 1, que discutiu problemas históricos e problemas envolvendo raciocínio quantitativo: números, quantidades, relações e operações.

Quadro 2: Fase-2 - Consolidação

\begin{tabular}{l} 
Descrição Sucinta das Atividades ( $\mathbf{2}^{\mathbf{0}}$ semestre do 1ªno) \\
\hline - Curso-2 de formação continuada: "Resolução de Problemas com Números \\
Inteiros por meio de Jogos" \\
-Participação nas sessões de formação: realização das atividades propostas, discussão \\
sobre as resoluções. \\
-Auxílio nas filmagens, organização da documentação de cada encontro, distribuição \\
de materiais e registro das discussões em diários de anotações. \\
-Relato de experiências de sala de aula. \\
- Encontros de estudos do grupo \\
-Análise dos protocolos de alunos relativos às aplicações em sala de aula de atividades \\
adaptadas pelo grupo. \\
-Atuação no evento I Seminário Integrado do Observatório da Educação: Parcerias \\
que promovem aprendizagem, envolvendo: planejamento e preparo da apresentação \\
em mesa redonda sobre as experiências em sala de aula, apresentação de pôster e \\
exposição de materiais educativos. \\
-Elaboração de relatório anual de bolsista.
\end{tabular}

Fonte: Acervo próprio

No segundo semestre, da mesma maneira que ocorreu no primeiro, os cinco 
professores do grupo participaram da formação continuada, no caso, o Curso 2, quando foram discutidos alguns jogos como estratégia para a inserção de resolução de problemas na sala de aula. Simultaneamente, esses professores participaram de ações diversificadas nos encontros de estudos do grupo ampliando e aprofundando seus conhecimentos teóricos e práticos. Um aspecto que vale ressaltar foi ter havido a oportunidade, já no segundo semestre do primeiro ano, do grupo participar ativamente de um evento científico (Seminário), apresentando as experiências desenvolvidas em sala de aula, suas produções e a construção de materiais didáticos. Além disso, como uma das tarefas como bolsistas, cada professor do grupo preparou um relatório anual sobre suas atividades, o que foi mais uma oportunidade de refletir sobre sua trajetória como integrante do grupo.

Quadro 3: Fase-3 - Manutenção

\begin{tabular}{|l|}
\hline \multicolumn{1}{|c|}{ Atividades - Fase Manutenção $\left(1^{\mathbf{o}}\right.$ semestre do $2^{\circ}$ ano $)$} \\
\hline • Encontros de estudos do grupo \\
-Planejamento dos rumos do grupo para o segundo ano. \\
-Elaboração de atividades para novas aplicações nas salas de aula. \\
-Estudos sobre os campos conceituais aditivo e multiplicativo. \\
-Realização de oficina para professores. \\
-Estudos teóricos sobre Resolução de Problemas. \\
-Preparo de artigo científico para ser submetido a evento de Educação Matemática. \\
-Proposta de oficina de jogos para desenvolver aos professores no evento de Educação \\
Matemática.
\end{tabular}

Fonte: Acervo próprio

A partir do segundo ano, as atividades se intensificaram nos encontros do grupo, oportunizando aos professores a também criarem em seus contextos de sala de aula as atividades, a partir das reflexões e discussões ocorridas nos encontros do grupo.

Nesse segundo ano, os professores demonstraram atitudes colaborativas, principalmente ao elaborarem a organização de Oficinas, bem como a produzirem artigos retratando suas reflexões sobre as práticas vivenciadas. Ficou evidenciado que a oportunidade dada aos professores de sentirem autores de suas produções favoreceu o desenvolvimento de uma postura investigativa sobre a própria prática, o compartilhamento das reflexões e o surgimento de criações coletivas.

Quadro 4: Fase-4 - Integração

\begin{tabular}{|l|}
\hline \multicolumn{1}{|c|}{ Atividades - Fase: Integração $\left(2^{\circ}\right.$ semestre do $2^{\circ}$ ano $)$} \\
\hline • Encontros de estudos do grupo \\
-Estudos teóricos sobre resolução de problemas e aula exploratório-investigativa. \\
-Providências para realização de videoconferência. \\
-Preparo de apresentações para comunicações científicas em evento. \\
-Preparo de oficina de jogos para submeter a evento de Educação Matemática. \\
-Participação na videoconferência "Ensino Exploratório da Matemática". \\
\hline
\end{tabular}


-Desenvolvimento de um projeto docente com a aplicação de atividade investigativa em sala de aula.

-Elaboração de artigo para ser apresentado como comunicação científica em evento científico.

-Realização de oficina sobre jogos envolvendo operações com números inteiros não positivos.

-Elaboração de relatório anual de bolsista.

\section{Fonte: Acervo próprio}

As atividades desenvolvidas na quarta fase tiveram a intenção de propiciar aos professores participantes do grupo de estudos vivenciar situações nas quais pudessem rever conceitos matemáticos, refletir e discutir sobre possíveis estratégias de ensino. Essa retomada de conceitos e de estratégias de ensino propiciou ao grupo ir além de suas práticas em suas salas de aulas. Vale destacar que os professores tomaram a iniciativa de propor e realizar uma Oficina sobre jogos, primeiro em suas respectivas escolas e depois em evento científico, desta forma assumindo papel de formadores. $\mathrm{Na}$ verdade, a vivência desses professores nas atividades nos cursos e no grupo de estudo, produzindo, dialogando com pesquisadores - tal como ocorreu na videoconferência e nos eventos - contribuiu para desenvolverem mais segurança em relação ao conteúdo matemático, ao ensino e à autonomia profissional docente. Como anteriormente mencionado, para ensinar é preciso que se aprenda sempre, ou seja, o professor se reinventa na medida em que reconstrói seus conhecimentos.

\section{Análise e Resultados}

A interpretação e análise dos depoimentos orais e escritos dos professores participantes durante os encontros ocorridos nos cursos e no grupo de estudos nos permitiu identificar a presença de categorias envolvidas no processo de constituição de um grupo colaborativo de professores. Para tanto, utilizamos as categorias pré-definidas por Lobo da Costa (2004), ligadas às características do trabalho colaborativo, denominadas: C1-Reflexão compartilhada, C2-Aprendizagem, C3- Ações docentes, C4- Ações de formação, C5-Pesquisa sobre a prática, C6- Troca de experiências, C7 - Representatividade do pensamento, C8Parceria; C9- Metas compartilhadas, C10- Compromisso com o grupo, C11- Confiança, C12Participação voluntária, C13- Diálogo/Interação, C14- Desenvolvimento da autonomia e C15 Reflexão sobre a prática.

Dentre essas categorias pré-definidas, a presente análise dos depoimentos do grupo de estudos, identificou treze categorias: C1, C2, C3, C4, C5, C6, C8, C9, C10, C11, C13, C14 e C15 e uma nova categoria emergente, que denominamos de C16 - Reflexão sobre a aprendizagem do aluno. No quadro 5, a seguir, apresentamos as categorias (pré-definidas e a emergente) com a respectiva descrição: 
DOI: http://dx.doi.org/10.20396/zet.v24i3.8648094

Quadro 5: Descrição das Categorias Identificadas no Grupo de Estudos

\begin{tabular}{|c|c|c|}
\hline Código & Categoria & Descrição \\
\hline $\mathrm{C} 1$ & Reflexão compartilhada & Expressa ideias e indagações \\
\hline $\mathrm{C} 2$ & $\begin{array}{l}\text { Reflexão sobre própria } \\
\text { aprendizagem }\end{array}$ & $\begin{array}{l}\text { Reconhece a própria aprendizagem } \\
\text { (específica e pedagógica do conteúdo). }\end{array}$ \\
\hline C3 & Ações docentes & $\begin{array}{l}\text { Relata experiências realizadas na sala de } \\
\text { aula. }\end{array}$ \\
\hline $\mathrm{C} 4$ & Ações de formação & Relata experiências como formador. \\
\hline $\mathrm{C5}$ & Pesquisa sobre a prática & $\begin{array}{l}\text { Demonstra ações investigativas sobre a } \\
\text { própria prática. }\end{array}$ \\
\hline C6 & Troca de experiências & $\begin{array}{l}\text { Discorre sobre conteúdos e atividades } \\
\text { práticas. }\end{array}$ \\
\hline $\mathrm{C} 8$ & Parceria & $\begin{array}{l}\text { Manifesta sentimento de solidariedade e } \\
\text { alianças. }\end{array}$ \\
\hline C9 & Metas compartilhadas & $\begin{array}{l}\text { Demonstra busca para atingir objetivos } \\
\text { comuns. }\end{array}$ \\
\hline $\mathrm{C} 10$ & Compromisso com o grupo & $\begin{array}{l}\text { Declara atitudes comprometidas com o } \\
\text { outro }\end{array}$ \\
\hline $\mathrm{C} 11$ & Confiança & $\begin{array}{l}\text { Manifesta sentimentos de confiança e } \\
\text { pertinência }\end{array}$ \\
\hline $\mathrm{C} 13$ & Diálogo/Interação & Reconhece o valor dos diálogos no grupo \\
\hline $\mathrm{C} 14$ & Desenvolvimento da Autonomia & Demonstra segurança nas decisões. \\
\hline $\mathrm{C} 15$ & Reflexão sobre a prática & $\begin{array}{l}\text { Reconstrói a prática pedagógica } \\
\text { vivenciada. }\end{array}$ \\
\hline $\mathrm{C} 16$ & $\begin{array}{l}\text { Reflexão sobre aprendizagem do } \\
\text { aluno }\end{array}$ & $\begin{array}{l}\text { Reconhece o processo de aprendizagem } \\
\text { do aluno }\end{array}$ \\
\hline
\end{tabular}

Fonte: Acervo próprio

A partir desses dados desenvolvemos uma análise relacional dos depoimentos orais e escritos dos professores participantes em cada uma das fases constituintes das ações formativas, ou seja, as fases: Início de convívio, Consolidação, Manutenção e Integração. Para isto, utilizamos a versão 3.5 do software CHIC que gerou, em cada uma das fases, um gráfico que nos permite visualizar por meio da árvore de similaridade as relações entre as categorias (pré-definida e emergente), identificadas nos depoimentos orais e escritos dos professores participantes.

Para utilizar o CHIC, elaborou-se inicialmente uma tabela binária para cada uma das fases. Essa tabela foi construída tendo na primeira linha as categorias (pré-definida e emergente) codificadas como variáveis (por exemplo: $\mathrm{C} 1, \mathrm{C} 2$, etc.) e na primeira coluna os registros dos depoimentos codificados (por exemplo: F1R1, F1R2, etc.). Os valores (0 ou 1) foram lançados na tabela de dupla entrada, indicando presença ou ausência da categoria correspondente ao registro do depoimento feito pelos professores do grupo participante. 
Assim, as tabelas feitas em Excel (com extensão do arquivo.csv) correspondentes a cada uma das fases foram carreadas pelo software CHIC, gerando quatro gráficos: as árvores de similaridade. Em cada árvore é possível visualizar os nós e as classes de variáveis (as categorias) mapeadas em níveis hierárquicos de similaridade. A seguir, a figura 1 mostra a Árvore de similaridade da Fase-1.

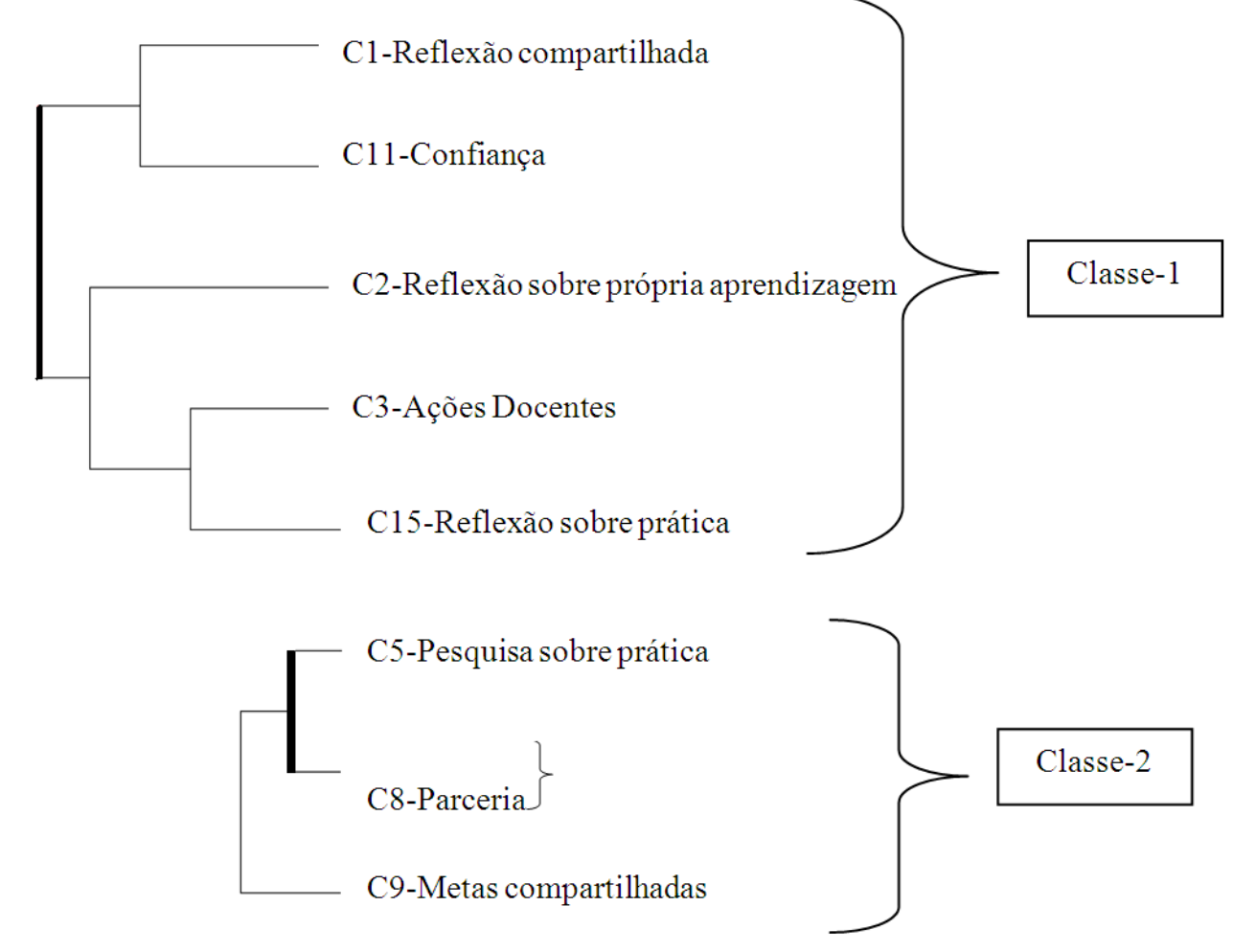

Figura 1: Árvore de similaridade da Fase-1 Início de Convívio

Fonte: Acervos dos autores

A visualização da árvore de similaridade mostra as relações de oito categorias prédefinidas, as quais foram identificadas na fase-1: Início de Convívio do grupo durante as ações desenvolvidas tanto nos momentos de formação continuada como nos encontros do grupo de estudos.

Observa-se que a árvore de similaridade apresenta duas classes, sendo a Classe-1 formada pelas categorias [C1, C11, C2, C3 e C15] e a Classe-2 pelas categorias [C5, C8 e C9]. Provavelmente o fato das duas classes se apresentarem separadas deva-se à existência no grupo de dois focos de reflexão vivenciados pelos professores participantes.

A Classe-1 mostra o nó [C3 C15] que se apresenta com um forte nível de similaridade, que por sua vez está ligado à categoria [C2], indicando a importância de se trazer as experiências docentes vivenciadas pelos professores para a reflexão no grupo, uma vez que ao refletirem sobre elas, os professores reconhecem que aprendem a lidar melhor com sua prática em sala de aula. 
O interessante é que a configuração desta classe está ligada também de forma significativa (sinalizada com a linha em negrito) ao nó [C1 e C11] que nos dá indícios interpretativos de que o sentimento de confiança dos professores com seus pares no grupo possibilitou o compartilhamento de suas reflexões, conforme ilustra o extrato do registro textual do Prof-B:

[...] estava caindo na mesmice, ao ministrar minhas aulas, eu já não aguentava mais, apenas com giz e lousa. Por meio da aplicação de jogos que aprendi na formação, isso abriu minha mente. Consigo agora dar uma aula mais dinâmica, onde os alunos participam em sua maioria, pois foi os jogos que proporcionaram essa mudança tanto na minha prática docente como no envolvimento dos alunos [Registro transcrito da gravação de áudio do Prof-B].

A Classe-2 composta pelo nó [C5 e C8] apresenta o maior nível de similaridade e significativo (sinalizada com a linha em negrito) que está ligado à categoria [C9]. Essa constituição da classe-2 revela que alguns professores no grupo já se expressam na fase-1 evidenciando que para desenvolver a investigação sobre a própria prática é preciso ter companheirismo no grupo e objetivos em comum, conforme ilustra o extrato do registro textual do Prof-D:

[...] percebo a existência de um grande respeito entre nós, além de muita solidariedade nas horas em que um precisa do outro para realizar o trabalho... [Registro transcrito da gravação de áudio do Prof-D].

Fica evidenciado, portanto, que no início da constituição de um grupo de estudos a confiança e o respeito pessoal e profissional entre os componentes são fundamentais para que seja criado um clima de companheirismo entre todos e de envolvimento sobre as questões abordadas nos momentos de estudos. A seguir a figura 2 mostra a Árvore de similaridade da Fase-2 Consolidação: 
DOI: http://dx.doi.org/10.20396/zet.v24i3.8648094

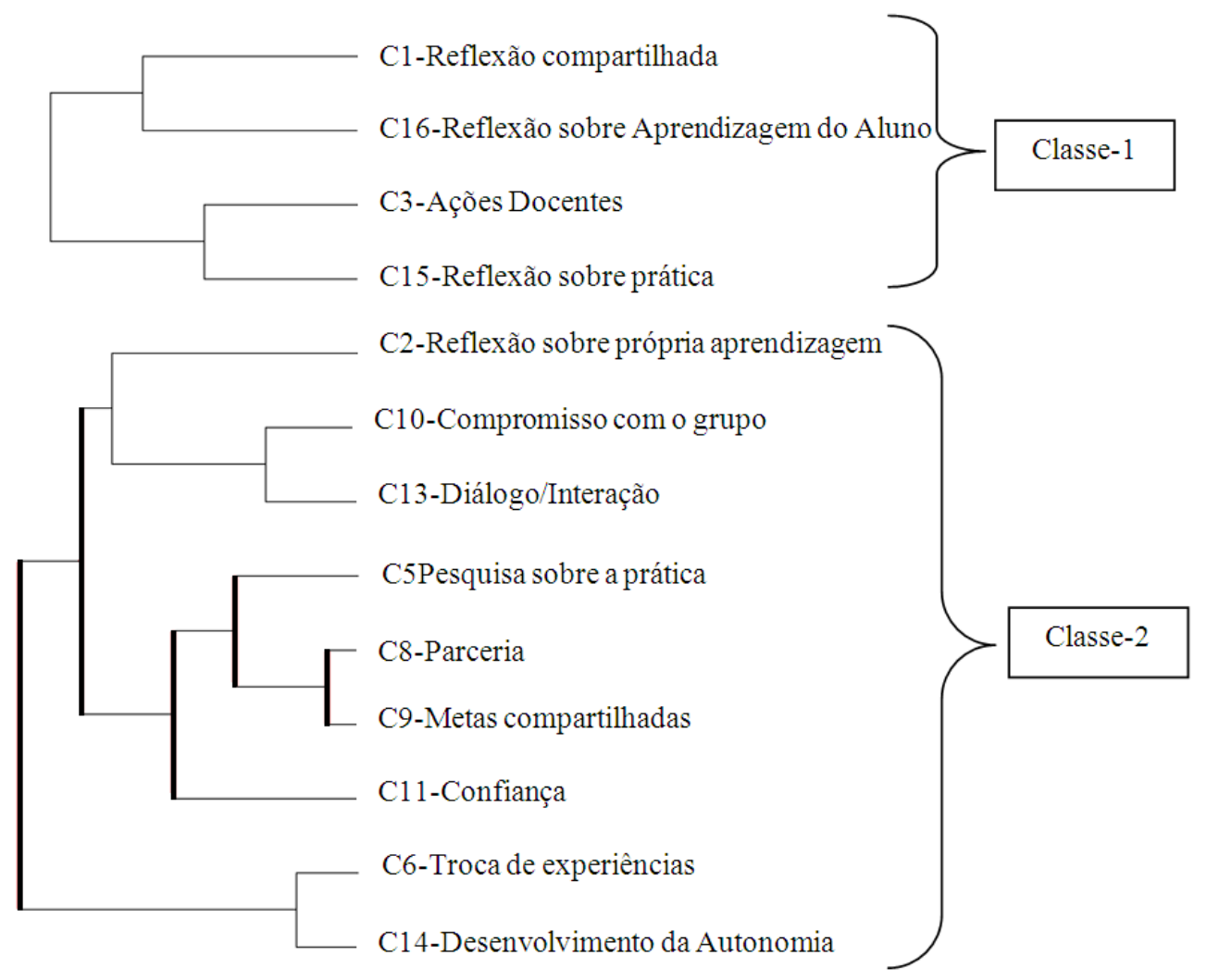

Figura 2: Árvore de similaridade da Fase-2 Consolidação

Fonte: Acervos dos autores

A árvore de similaridade da Fase 2 apresenta uma nova configuração de treze categorias sendo doze delas as pré-definidas e uma categoria a que emergiu nesse contexto do grupo, C16- Reflexão sobre Aprendizagem do Aluno. Ressaltamos que nessa fase-2 denominada de Consolidação, os professores em suas atividades no curso de formação relatavam suas experiências de sala aula, ou seja, nesse processo elas revisitavam as próprias práticas e, consequentemente, na acepção de Schön (1992) refletiram sobre suas práticas e, segundo Zeichner $(1993 ;$ 2003), refletiam de forma compartilhada com os colegas da turma.

Além disso, nos encontros de estudos do grupo, as atividades de intervenção em sala de aula previamente planejadas em conjunto na fase-1 e aplicadas na fase-2 foram discutidas e, buscando compreender o processo de resolução dos alunos, as análises foram aprofundadas com suporte teórico. Isso fica evidenciado no nó formado pelas categorias [C1 e C16] presente na Classe-1 da árvore da figura-2. Esse nó, por sua vez, apresenta-se relacionado ao nó [C3 e C15] tal como apareceu na árvore anterior da figura-1, reafirmando a importância de a experiência docente fazer parte das reflexões dos professores no grupo, conforme ilustra o extrato do registro textual do Prof-C:

Os problemas estavam muito fora da realidade, me perguntei se os alunos conseguiriam resolvê-los. Me surpreendi com os resultados, [...] os alunos realizaram as atividades de maneira simples, por meio de estratégias pessoais... [Registro transcrito da gravação de áudio do Prof-C]. 
A Classe-2 dessa fase de Consolidação também mostra a continuidade da relação entre as categorias [C8, C9 e C3] com forte nível de similaridade, estatisticamente significativa (sinalizada com a linha em negrito), indicando que a base do grupo é o sentimento de confiança entre seus participantes.

Outro aspecto interessante mostrado na árvore de similaridade é o encadeamento das relações entre as categorias [C10, C13 e C2], revelando que na fase de consolidação do grupo as interações entre os professores foram se intensificando e, com isso, as atitudes de comprometimento um com o outro potencializaram o reconhecimento de que no grupo os integrantes estavam aprendendo tanto sobre os conteúdos matemáticos abordados nos cursos como na maneira de lidar com esses conteúdos em sala de aula, conforme ilustra o extrato do registro textual do Prof-C:

[...] geralmente apareciam dúvidas... Nestas situações uma professora [colega do grupo] colaborava com a outra, explicando como resolver ou ainda refletindo sobre como fariam para desenvolver aquele determinado jogo em sala de aula. [Registro transcrito da gravação de áudio do Prof-C].

De fato, aliado a esse sentimento revelado pelo grupo de professores, a presença do nó formado pelas categorias [C6 e C14] com forte nível de similaridade, evidencia que a troca de experiências e saberes relacionados ao domínio do conteúdo específico, no caso de matemática, integrada às atividades práticas revelou ampliação do conhecimento pedagógico do conteúdo, na perspectiva de Shulman (1986), que é aquele que permite ao professor ter autonomia no seu fazer pedagógico.

Outra atividade realizada pelo grupo de estudos nessa fase- 2 foi a participação dos professores no I Seminário integrado do Observatório da Educação em que elas tiveram a oportunidade de apresentar relatos sobre suas experiências de sala de aula para um público convidado da universidade (mestrandos, doutorandos e docentes) e profissionais da Secretaria de Educação do Estado (Dirigentes, supervisores, professores, coordenadores). Além de apresentar Pôster e os materiais educacionais produzidos para o Projeto nos encontros de estudo do grupo. Os extratos dos registros textuais dos Profs. A e C, mostrados a seguir ilustram esse momento de reflexão:

O Seminário foi uma oportunidade de discutir experiências de sala e adaptações feitas para os problemas e jogos discutidos durante a formação. [Registro transcrito da gravação de áudio do Prof-A].

Nossa! Estou me sentido muito importante em realizar e expor esse trabalho. A participação no Seminário foi relevante para mim, fiquei feliz ao produzir o pôster para mostrar e falar sobre as experiências didáticas. [Registro transcrito da gravação de áudio do Prof-C].

Essa troca de experiência envolvendo diferentes atores da Educação durante a socialização favoreceu ao grupo de professores o sentimento de valorização profissional possibilitando o envolvimento desses professores em seu próprio processo de formação. 
DOI: http://dx.doi.org/10.20396/zet.v24i3.8648094

Dando continuidade à análise, apresentamos a seguir a figura 3: Árvore de similaridade da Fase-3 Manutenção:

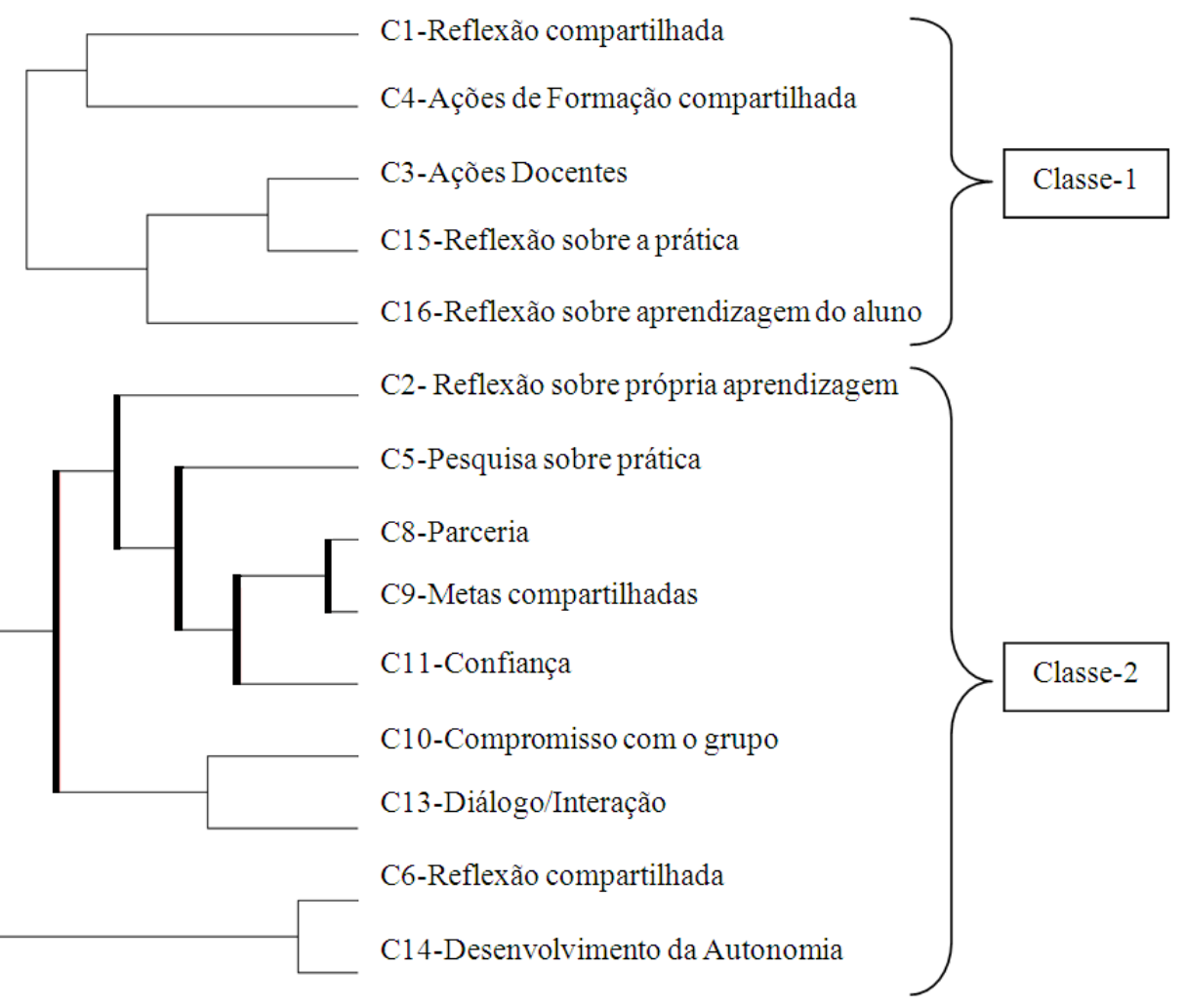

Figura 3: Árvore de similaridade da Fase-3 Manutenção

Fonte: Acervos dos autores

A árvore de similaridade apresenta-se constituída por quatorze categorias e com uma configuração semelhante à árvore anterior, da fase de Consolidação, embora se destaque uma ampliação na Classe-1 com o surgimento da categoria [C4] com forte nível de similaridade com [C1], indicando a importância das ações realizadas de formação de outros professores conforme o quadro 3. Podemos ainda observar na árvore, na Classe-1, a presença de um encadeamento das categorias [C3, C15 e C16] indicando e confirmando a importância dos relatos das experiências vivenciadas em sala de aula no grupo, evidenciando que a reflexão sobre a prática permitiu envolver também a reflexão sobre como o aluno aprende, conforme ilustra o extrato do registro textual do Prof-B:

[...] é interessante observar os procedimentos utilizados para a resolução dos problemas. Nunca havia refletido e investigado como o aluno pensa, resolve um problema, faz um registro. [Registro transcrito da gravação de áudio do Prof-B].

Nesta mesma Classe-1 aparece o nó [C4 e C1] que apresenta um nível de similaridade discreto, mas a sua presença é interessante, porque nos dá um indício interpretativo de que as ações desenvolvidas no grupo, conforme mostra o quadro 3, envolvendo tanto estudos teóricos como a preparação de oficinas a serem desenvolvidas no evento e a construção de artigo científico contribuíram para o desenvolvimento de práticas formadoras, ou seja, surge 
DOI: http://dx.doi.org/10.20396/zet.v24i3.8648094

o desempenho de um novo papel, qual seja o de formador (além do papel de aprendiz e docente que desempenhavam nas fases anteriores) como ilustra o extrato do registro textual do Prof-E:

A diretora da escola solicitou que eu apresentasse depoimento para os meus pares sobre a importância de realizar um trabalho diferenciado com os alunos e também preparasse uma oficina sobre resolução de problemas para os professores da escola. [Registro transcrito da gravação de áudio do Prof-E].

Vale ainda ressaltar que na Classe-2 que a configuração significativa e de maior nível de similaridade continua se mantendo com a presença das categorias [C8, C9, C11, C5 e C2] que por sua vez se interligam ao nó [C10 e C13], mostrando que os sentimentos de solidariedade, confiança e respeito constituem a base para que cada componente do grupo se comprometa com o desenvolvimento pessoal e coletivo. A seguir a figura 4 mostra a Árvore de similaridade da Fase-4 Integração:

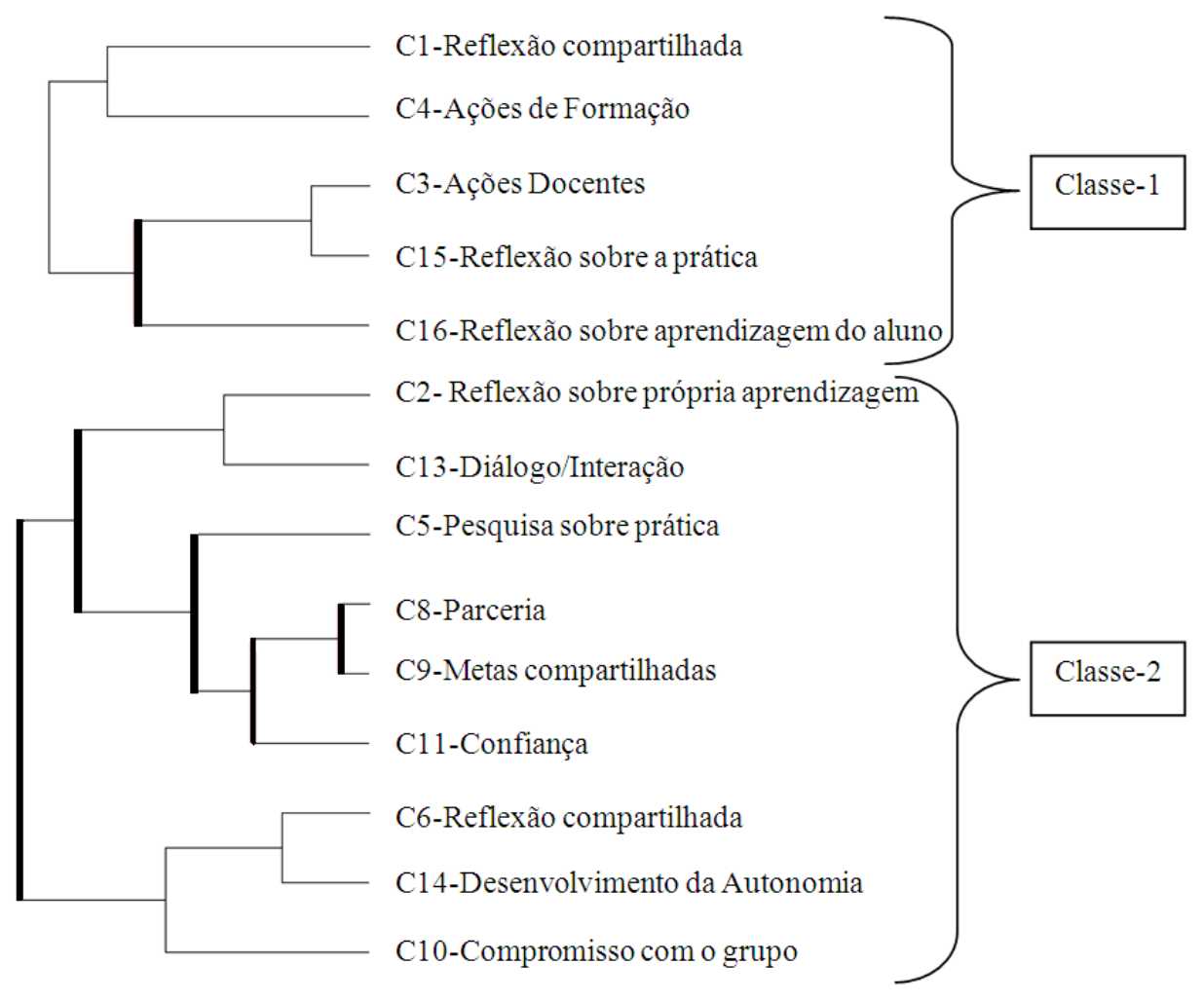

Figura 4: Árvore de similaridade da Fase-4 Integração

Fonte: Acervos dos autores

A árvore de similaridade da fase de Integração apresenta a Classe-1 com a mesma configuração da árvore anterior, ou seja, da fase de Manutenção em relação a presença das categorias [C1, C4, C3, C15 e C16] e de suas interrelações. Este fato, provavelmente nos traz a confirmação de que o desenvolvimento de ações de formação realizadas pelo grupo de 
professores em seus contextos de atuação propiciou o aprofundamento reflexivo sobre a prática pedagógica e sobre o processo de aprendizagem dos alunos.

Os extratos dos registros textuais dos Prof. A e E, mostrados a seguir, ilustram esse momento de reflexão sobre aprendizagem do aluno:

[...] os temas discutidos foram de grande importância... pois refletimos um pouco mais como funciona a mente das crianças, foi grande a interação deste grupo de estudo... [Registro transcrito da gravação de áudio do Prof-A].

[...] é importante analisar os registros dos alunos, questionando-os sobre o que aprenderam, isto é, não se trata simplesmente de corrigir a questão do aluno e atribuir certo ou errado, mas de procurar compreender os raciocínios, estratégias e possibilidades expostas no registro do aluno. [Registro transcrito da gravação de áudio do Prof-E].

A Classe-2 apresenta um encadeamento com presença das categorias [C5, C8, C9 e C11], que também aparece de maneira constante nas fases anteriores (de Consolidação e Manutenção), vivenciadas pelo grupo de estudos. Isto nos mostra que a essência do grupo requer confiança, objetivos em comum, ações investigativas e parceria.

A novidade nessa classe é a presença do nó formado pelas categorias [C2 e C13] com forte nível de similaridade, indicando que nessa fase a interação entre os participantes do grupo favoreceu a reflexão sobre a própria aprendizagem. $\mathrm{O}$ fato de o grupo ter interagido, por meio de uma videoconferência com um pesquisador internacional, estabelecendo parcerias para aplicar as atividades discutidas em sala de aula e, a partir dessa experiência, produzirem trabalhos de comunicação científica para serem apresentados em eventos, potencializou o processo reflexivo dos professores, desenvolvimento da autonomia e o fortalecimento do grupo, no sentido de assumir uma postura colaborativa de aprendizagem.

\section{Considerações Finais}

Com o objetivo de compreender o processo de constituição de um grupo de estudos do Projeto OBEDUC Práticas, analisamos a trajetória desse grupo, que teve a oportunidade de vivenciar diferentes ações em contexto de formação e em encontros para estudos e discussões sobre a prática do professor de Matemática.

A partir das categorias identificadas nos depoimentos dos professores participantes do estudo, durante as quatros fases denominadas "Início de convívio", "Consolidação", "Manutenção" e "Integração" e do tratamento estatístico possibilitado pelo uso do software CHIC, foi possível identificar os elementos que contribuíram para o desenvolvimento profissional daqueles professores.

Destacamos que na constituição do grupo, como uma rede de aprendizagem, foi fundamental o estabelecimento de um clima de relações de confiança e o respeito pessoal e profissional para um trabalho colaborativo entre os professores envolvidos no Projeto. 
DOI: http://dx.doi.org/10.20396/zet.v24i3.8648094

As experiências vivenciadas em sala de aula e as discussões no grupo evidenciaram a reflexão sobre a prática envolvendo também a reflexão sobre como o aluno aprende. As diversas metodologias utilizadas nos cursos de formação e nos encontros de estudos do grupo, envolvendo os conteúdos matemáticos e estratégias pedagógicas, contemplaram aspectos teóricos e práticos bem como o compartilhamento das experiências em vários contextos: no grupo, na escola, nos eventos (seminário, oficinas, videoconferência). Tais reflexões, em nosso entender, contribuíram para o desenvolvimento de um novo papel, qual seja, o de formador, além de propiciar a construção de uma cultura de grupo, na qual foi possível a cada participante ensinar e aprender com o outro, ampliando o leque de alternativas para o desenvolvimento profissional do professor.

\section{Agradecimentos}

À CAPES/Inep e ao Programa Observatório da Educação, pelo subsídio ao Projeto "OBEDUC Praticas" (Edital 49/2012) e à pesquisa referente a este artigo.

\section{Referências}

Almouloud, S. (1992). L'ordinateur, outitl d'aide à l'apprentissage de la démonstration et de traitement de données didactiques. Tese de Doutorado em Educação Matemática. Rennes: Université de Rennes I.

Amado, J. (2013). Manual de investigação qualitativa em educação. Coimbra: Imprensa da Universidade de Coimbra.

Boavida, A. M. \& Ponte, J. P. (2002). Investigação colaborativa: Potencialidades e problemas. In GTI (Ed.). Reflectir e investigar sobre a prática profissional. (pp.4355). Lisboa: APM

Boesing, C. (2009). A prática da pesquisa nas aulas de matemática: vivências de professores do ensino fundamental que integram um grupo de estudos. Dissertação de Mestrado em Educação, Ciências e Matemática. Porto Alegre: Pontifícia Universidade Católica do Rio Grande do Sul.

Etcheverria, T.C. (2008). Educação continuada em grupos de estudos: possibilidades com foco no ensino da geometria. Dissertação de Mestrado em Educação em Ciências e Matemática. Porto Alegra: Pontifícia Universidade Católica do Rio Grande do Sul.

Ferreira, A. C. (2003). Metacognição e desenvolvimento profissional de professores de matemática: uma experiência de trabalho colaborativo. Tese de Doutorado em Educação. Campinas (SP): Universidade Estadual de Campinas.

Gimenes, J. (2006). Contribuições de um grupo de estudos para a formação matemática de professoras que lecionam nas séries iniciais. Dissertação de Mestrado em Educação Matemática. Rio Claro (SP): Universidade Estadual Paulista. 
DOI: http://dx.doi.org/10.20396/zet.v24i3.8648094

Gimenes, J. \& Penteado, M.G. (2008). Aprender matemática em grupo de estudos: uma experiência com professoras de séries iniciais. Zetetiké. Unicamp, 16 (29), 73-92

Gras, R. \& Almouloud, S. (2002). A implicação estatística usada como ferramenta em um exemplo de análise de dados multidimensionais. Revista Educação Matemática Pesquisa. Programa de Estudos Pós-Graduados em Educação Matemática. PUCSP. São Paulo: EDUC, 4 (2), 75-88.

Gras, R. Couturier. R. (2010). Spécificités de l'Analyse Statistique Implicative (A.S.I.) par rapport à d'autres mesures de qualité de règles d'association. In Régnier, J.C., Gras, R., Spagnolo, F. \& Paola, B. D. (Eds). A.S.I. 5 - Analyse Statistique Implicative. Objet de recherche et de formation en analyse des données, outil pour la recherche multidisciplinaire. Prolongement des débats. Quaderni di Ricerca in Didattica Matematica. 1(20), pp.19-57, Palermo. Retirado em 15 de junho, 2011, de <http://math.unipa.it/ grim/QRDM_20_Suppl_1.htm>.

Hargreaves, A. (1998). Os professores em tempos de mudança: o trabalho e a cultura dos professores na idade pós-moderna, Lisboa: Ed McGraw-Hill.

Lima, L. F. (2009). Grupo de estudos de professores e a produção de atividades matemáticas sobre funções utilizando computadores. Dissertação de Mestrado em Educação Matemática. Rio Claro (SP): Universidade Estadual Paulista.

Lobo da Costa, N. M. \& Prado, M.E.B.B. (2012). Mathematics Teacher Continuing Education: Fostering the Constitution of a Learning Network. REDIMAT - Journal of Research in Mathematics Education. 1, 136-158.

Lobo da Costa, N. M. (2004). Formação de professores para o ensino da matemática com a informática integrada à prática pedagógica: exploração e análise de dados em bancos computacionais. Tese de Doutorado em Educação. São Paulo: Pontifícia Universidade Católica de São Paulo.

Lopes, C. A. E. (2003) O conhecimento profissional dos professores e suas relações com Estatística e Probabilidade na Educação Infantil. Tese de Doutorado em Educação. Campinas: FE/Unicamp.

Mädche, F. C. \& Mallmann, T. (2006). Grupo de estudos: o sonho que se sonha em conjunto se torna realidade. São Leopoldo: Unisinos.

Murphy, C. \& Lick, D. (1998). Whole faculty study groups: A powerful way to change schools and enhance learning. California: Corwin.

Ponte, J. P. (1997). O conhecimento profissional dos professores de matemática (Relatório final do Projecto O saber dos professores: Concepções e práticas). Lisboa: DEFCUL.

Prado, M.E.B.B. (2008). Mapeando registros textuais no CHIC para formação de professores. In: Okada. A. (org.). Cartografia cognitiva: mapas do conhecimento para pesquisa, aprendizagem e formação docente. (pp. 339-352). Cuiabá: KCM. 
DOI: http://dx.doi.org/10.20396/zet.v24i3.8648094

Prado, M.E.B.B. \& Lobo da Costa, N. M. (2012). Grupo de Estudos e o professor de Matemática: Revendo a Prática no Contexto Escolar. Anais do V SIPEM Seminário Internacional de Pesquisa em Educação Matemática. Petrópolis/RJ: Sociedade Brasileira de Educação Matemática.

Schön, D. (1992). Formar Professores como Profissionais Reflexivos. In: Nóvoa, A. (coord.). Os professores e a sua formação. Lisboa, Portugal: Publicações Dom Quixote Instituto de Inovação Educacional.

Shulman, L. (1986). Those Who Understand: Knowledge Growth in Teaching. Educational Researcher, 15 (2), 4-14.

Shulman, L. (1989). Teaching alone, learning together: needed agendas for the new reforms. San Antonio, USA: Conferência na Trinity University.

Silva, G. H. G. da. (2010). Grupos de estudo como possibilidade de formação de professores de matemática no contexto da geometria dinâmica. Dissertação de Mestrado em Educação Matemática. Rio Claro (SP): Universidade Estadual Paulista.

Vieira, E. V. (2013). Grupo de estudos de professores e a apropriação de tecnologia digital no ensino de geometria: caminhos para o conhecimento profissional. Tese de Doutorado em Educação Matemática. Universidade Anhanguera de São Paulo.

Vygotsky, L. S. (1984). Formação social da mente: o desenvolvimento dos processos psicológicos superiores. Tradução por J. Cipolla Neto. São Paulo: Editora Martins Fontes.

Zeichner, K. M. (1993). A formação reflexiva de professores: idéias e práticas. Lisboa: Educa.

Zeichner, K. M. (2003). Formando professores reflexivos para a educação centrada no aluno: possibilidades e contradições. In: Barbosa, R. L. L. (Org.). Formação de educadores: desafios e perspectivas. (pp.35-55). São Paulo: Editora UNESP. 